\title{
A mortality study of shipyard workers with pleural plaques
}

\author{
D. E. FLETCHER \\ X-Ray Department, North Lonsdale Hospital, Barrow-in-Furness
}

\begin{abstract}
Fletcher, D. E. (1972). Brit. J. industr. Med., 29, 142-145. A mortality study of shipyard workers with pleural plaques. Mild asbestos effects are seen frequently in shipyard workers. It is known that exposure of this type may be associated with mesothelioma, but it is not generally thought that an increased bronchial carcinoma risk exists unless there is pulmonary fibrosis. A number of cases of both types of malignant disease were seen in the Barrow hospitals, associated with pleural plaques. In view of this a retrospective survey was carried out.

All routine administrative chest films taken in the works clinic between 1960 and 1970 were reviewed, together with the films of the 1962 mass radiography session, and 408 men were found to have evidence of pleural plaques. The men were followed up from the year of diagnosis until 1970 and 65 men died in this period. A similar control group of 404 men was chosen and 56 of them died. Both groups were compared with the expected mortality of Barrow men of the same age groups. There were 16 bronchial carcinomas in the plaque series compared with an expected figure of 6.74 (P = 0.0047), while in the control series there were 7 bronchial carcinomas compared with 5.61 expected $(P=0.516)$. Three mesotheliomas occurred in the plaque series $(P=0.0002)$.
\end{abstract}

The shipbuilding industry uses many different asbestos products mainly in pipe lagging and in lining cabins and other rooms with asbestos-containing boards. Much asbestos cloth is used in electrical preheating and there are many other minor uses. Men of various trades work together in confined spaces, sharing each other's occupational hazards. Minor changes of asbestos effects are frequently seen. The Barrow shipyard is probably fairly representative of British shipbuilding practice and employs about 13000 men. Pleural plaques are found in approximately $5 \%$ of adult male shipyard workers in Barrow, while about $1 \%$ have radiological suspicion of pulmonary fibrosis which could be due to asbestos.

During the last few years a number of cases of thoracic malignant disease associated with pleural plaques have been seen in the Barrow hospitals; both mesotheliomas and bronchial carcinomas. It is recognized that mesothelioma frequently occurs after mild asbestos exposure not producing pulmonary fibrosis, but an increased risk of bronchial carcinoma in these circumstances is not generally accepted. It was felt that an epidemiological study should be carried out but permission could not be obtained for a prospective study. Hospital cases represented a medically biased sample so retrospective examinations of existing collections of routine administrative and mass survey films were used.

\section{Review of the literature}

There is considerable evidence of an association between diffuse malignant mesothelioma and asbestos exposure. In South Africa, Sleggs, Marchand, and Wagner (1961) found a history of asbestos exposure in 33 out of 34 cases, but only about one-third of 
their cases had pulmonary fibrosis. In Dresden, Anspach (1965) reported occupational or environmental exposure to asbestos in 19 out of 22 patients with pleural mesothelioma, but only 10 had asbestos bodies in the lungs or pulmonary fibrosis. In 42 Belfast cases reported by Elmes, McCaughey, and Wade (1965), 32 had an exposure history, mainly in the shipyards. Hägerstrand, Meurman, and Ödlund (1968) reported that of 35 mesotheliomas seen in the Swedish shipbuilding town of Malmö, only three had any evidence of pulmonary fibrosis.

In 1934 Wood and Gloyne reported two cases of asbestosis associated with bronchial carcinoma. In 1951, Gloyne noted that out of 121 necropsy cases of asbestosis, 17 had a primary lung tumour, an incidence of $14.1 \%$. Doll (1955) carried out a cohort study of men with over 20 years' employment in a Rochdale asbestos factory and showed a significant increase in the incidence of bronchial carcinoma associated with asbestosis. The risk was shown to have diminished since the Asbestos Industry Regulations were introduced in 1933. On the other hand, Jacob and Anspach (1965) showed that the risk of developing lung cancer had increased in Dresden. Improved working conditions resulted in fewer early deaths from cor pulmonale, and more workers lived long enough to develop thoracic cancer.

Braun and Truan (1958) found a slightly increased risk of lung cancer in Quebec asbestos miners but the result was not statistically significant. Mancuso and Coulter (1963) reported $10 \cdot 2 \%$ of lung cancers in 186 deaths of asbestos factory workers compared with an expected figure of $3 \%$. Enterline and Kendrick (1967) showed that asbestos textile workers had 2.3 times as many lung cancers as the general population, but for asbestos building board workers the figure was 1.3 times. None of these cohort studies referred to the number of men with pulmonary fibrosis or to their smoking habits.

A series of papers by Selikoff, Hammond, and Churg presented undoubted evidence of an increased bronchial carcinoma risk in New York asbestos insulation workers and referred to smoking habits. In the 1969 paper they referred to 94 successive deaths of men with over 20 years' exposure history, 24 of whom died of bronchial carcinoma. The expected figure was $2 \cdot 3$. They were able to show that smoking increased the risk 11.4 times and asbestos exposure with smoking 92.3 times. Just less than half their cases were confirmed at necropsy. Fifteen men died of asbestosis, but they do not say how many men had pulmonary fibrosis associated with other lesions.

Newhouse (1969) carried out a cohort study of male asbestos factory workers and demonstrated an increased risk of thoracic malignancy in men employed less than two years in a heavy exposure category and then followed for 16 years. Out of 34 deaths, there were 8 thoracic cancers compared with an expected figure of $2 \cdot 7$. The relative numbers of bronchial carcinomas and mesotheliomas were not given for this group.

\section{Routine chest films available for study}

There is no mass radiography unit in Barrow but regular visits are made by one of the regional units and at various times the shipyard has been included in the survey. Films and record cards are available only for the more recent examinations, the earliest being in July 1962. This was made on $100 \mathrm{~mm}$ film and covered 11347 people, 7357 men and 3990 women. Among the men were 5456 shipyard workers and 1901 other workers, many of whom had worked in shipbuilding previously.

There is also a large collection of full-size posteroanterior chest films at the works clinic, mostly taken for purely administrative reasons. Films are taken of all apprentices, most new entrants, and men engaged after a break in service. All men referred for a routine medical examination also have a chest film, and certain trades are examined regularly, especially laggers, welders, crane drivers, and foundry workers. Men working near radioactive sources are frequently examined, also those using certain types of equipment. Most joiners have been examined and several workshops and drawing offices have been surveyed when tracing tuberculosis contacts. There are a few films which were taken for the investigation of minor respiratory symptoms but as these introduced a medical bias they were discarded. There are 8706 sets of films, covering 8561 men and 145 women, some beginning in 1948 but most of them taken during the last 10 years. Many have had serial examinations. There is some overlap between these two film collections, 394 men being present in both. Combining the two, radiographs of 15524 men are available for study, most of them present or previous shipyard workers.

\section{Method of investigation}

To obtain an unbiased group of men for follow-up, the entire collection of films from the 1962 mass radiography survey and the clinic films were read without any identification details, and cases with pleural plaques were noted. The criteria used in diagnosis have been described (Fletcher and Edge, 1970). Record cards were then consulted and men were discarded if they would be under the age of 45 by the end of the survey period. This was done because it is unlikely that asbestos related malignancy would occur in younger age groups.

Four hundred and eight men were selected for follow-up and they were then traced through works records, hospital case notes, $x$-ray departmental records, electoral rolls, general practitioner records, and death certificates. In all fatal cases a particular effort was made to verify the cause of death from hospital records. No men were lost to follow-up, which extended from 1 July 1960 to 30 June 1970. 
The control series was a group of men without $x$-ray evidence of plaques, selected from the same film collections. From an alphabetical index of all the men in each part of the survey the control for each plaque case was the nearest man of the same trade within fiveyears of age with a chest film not showing plaques. There were originally 408 controls, who were then followed up in the same manner, but four could not be traced so the final control series consisted of 404 men. Owing to the method of selection some of these men were under 45 years of age in 1970. They all had normal chest $x$-rays during the period of study but all did not have recent films, and the possibility of some of them having developed plaques cannot be excluded. This was inevitable; insistence upon a recent normal chest film for control cases would have introduced deliberate selection. Because of these difficulties it was decided not to compare the two groups with each other but to compare each with an expected mortality.

The method of determining the expected mortality was based on the comparative composite cohort analysis array of Case and Lea (1955) with two slight alterations. First, they were dealing with a cohort all of whom were identified at the beginning of their survey, whereas in the present survey new cases diagnosed were added each year. Secondly, they used national mortality statistics, but in this study local statistics were judged to be a fairer comparison, as the mortality from bronchial carcinoma in Barrow was $13.4 \%$ higher than the national figure during the 10-year period. For this purpose death certificates and population figures were used to work out the mortality from all causes, bronchial carcinoma, and other cancers in men of each 10-year age group for all years from 1960 to 1970. The mortality from mesothelioma could not be computed in this manner owing to its rarity, but an overall figure was calculated for men of all age groups in a 10year period.

Starting with 1960 the number of men with plaques was noted in each age group and divided by two as the followup began on 1 July of that year. Men diagnosed later that year were assumed to join the survey half way through the period and counted as a quarter. In each age group the expected mortality was worked out. In determining the number of men studied in 1961, the survivors from 1960 were added to the new cases diagnosed in 1961, each of whom was assumed to be diagnosed in the middle of the year and was accordingly counted as one half. In this way the expected mortality in each year was determined from the actual number of men observed in that year. A similar chart was then prepared for the controls. When the individual years had been computed they were added together and the totals for the whole 10-year period are presented in the Table.

\section{Discussion}

The number of deaths due to all causes was higher than the predicted figure in both groups. The most striking difference was in the bronchial carcinomas which were 2.4 times the expected figure in the plaques series and 1.2 times the expected figure in the control series. There was almost double the incidence of the disease in men with plaques compared with men of similar trades without plaques. As explained earlier, the difference between the two series is likely to be underestimated as it was not known how many

TABLE

Results of A 10-year Follow-up Study

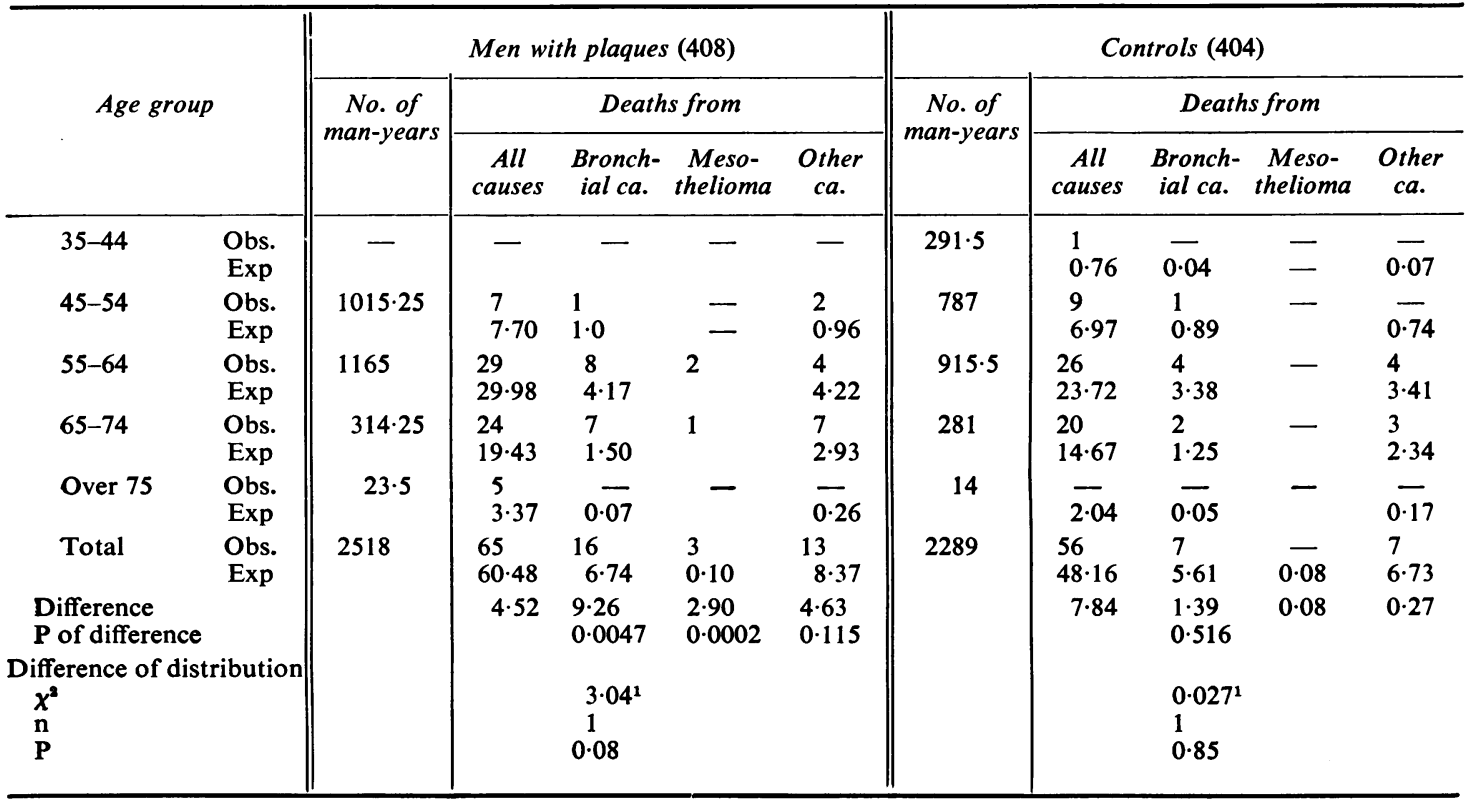

'With Yates' correction 
of the controls had developed plaques by the end of the survey. Comparison with the calculated expectation should be a more reliable estimate.

Five of the 16 bronchial carcinomas in the plaques series were proved at necropsy, two by biopsy examination after operation and three by bronchoscopy. Six cases were purely radiological diagnoses, not confirmed as they were too advanced for thoracotomy. On reviewing the films of these cases the diagnosis appeared to be correct and none of them seemed likely to be a misdiagnosed mesothelioma. None of the 16 cases had any radiological evidence of pulmonary fibrosis and only one of the five necropsy cases had slight fibrosis on histological examination.

The smoking habits of most of the men were not known, but as it could be suggested that there were more cigarette smokers among the plaque patients, a sample of men was asked about this. A questionnaire on smoking habits was completed by a random group of 696 general shipyard workers and by 132 consecutive men with pleural plaques when they attended the clinic for routine films. There were fewer nonsmokers among those with plaques but the difference was due entirely to pipe smoking; cigarette consumption was almost identical in the two groups. Out of 21 consecutive hospital cases of men with bronchial carcinoma and plaques, 2 were probably life-long non-smokers and 8 normally smoked less than 10 cigarettes a day. It does not seem likely that different smoking habits can explain the findings.

The occurrence of three mesotheliomas in the plaques series is obviously very significant considering the rarity of this disease in the general population. No cases occurred in the control series but during the same period there were some hospital admissions of mesotheliomas without radiological evidence of plaques. As these are a selected group no figure can be quoted for the incidence of mesothelioma in men with normal chest films except to note that it does occur. No peritoneal mesotheliomas have been seen.

There were also more cancers in other organs in the plaques series, not statistically significant and not involving any particular type of tumour.

\section{Conclusions}

Shipyard workers with pleural plaques have an increased risk of developing both bronchial carcinoma and mesothelioma when compared with the general male population of Barrow. Taking both types of thoracic malignant disease together, the risk is increased 2.8 times, the bronchial carcinomas alone $2 \cdot 4$ times. Shipyard workers without plaques may have a slightly increased risk of thoracic malignant disease, amounting to about 1.2 times the general male population in the town. There is no demonstrable association between pulmonary fibrosis and malig- nancy. Numbers are too small to allow comparison of different trades.

I should like to thank the management of Messrs. Vickers Ltd. for permitting me to publish the results of these studies. Dr. J. M. Stuart, the works medical officer, allowed me free access to his films and records and both he and his staff went to considerable trouble to trace work records. Dr. J. Capper, of the Mass Radiography Service, kindly loaned the 1962 survey films. Drs. A. W. Hay and J. L. Wild, Medical Officers of Health for Barrow and Ulverston respectively, loaned death certificates. Drs. J. Horrocks and D. Stansfield, pathologists, allowed me to examine their post-mortem reports. Some of the clerical work was finariced by a research grant provided by the Manchester Regional Hospital Board. The material was also used in an M.D. thesis submitted to the University of Leeds, and I am grateful to the University authorities for permission to publish it.

\section{References}

Anspach, M. (1965). Zur Ätiologie von Pleuraverkalkungen, Radiol. diagn. (Berl.), 6, 341-347.

Braun, D. C., and Truan, T. D. (1958). An epidemiological study of lung cancer in asbestos miners. Arch. industr. Hlth, 17, 634-653.

Case, R. A. M., and Lea, A. J. (1955). Mustard gas poisoning, chronic bronchitis and lung cancer. Brit.J. prev. soc. Med., 9, 62-72.

Doll, R. (1955). Mortality from lung cancer in asbestos workers. Brit. J. industr. Med., 12, 81-86.

Elmes, P. C., McCaughey, W. T. E., and Wade, O. L. (1965). Diffuse mesothelioma of the pleura and asbestos. Brit. med. J., 1, 350-353.

Enterline, P. E., and Kendrick, M. A. (1967). Asbestos-dust exposures at various levels and mortality. Arch. environm. Hlth, 15, 181-186.

Fletcher, D. E., and Edge, J. R. (1970). The early radiological changes in pulmonary and pleural asbestosis. Clin. Radiol., 21, 355-365.

Gloyne, S. R. (1951). Pneumoconiosis, a histological survey of necropsy material in 1205 cases. Lancet, 1, 810-814.

Hägerstrand, I., Meurman, L., and Ödlund, B. (1968). Asbestos bodies in the lungs and mesothelioma. Acta path. microbiol. scand., 72, 177-191.

Jacob, G., and Anspach, M. (1965). Pulmonary neoplasia among Dresden asbestos workers. Ann. N.Y. Acad, Sci., 132, 536-548.

Mancuso, T. F., and Coulter, E. J. (1963). Methodology in industrial health statistics. Arch. environm. Hlth, 6, 210-226.

Newhouse, M. L. (1969). A study of the mortality of workers in an asbestos factory. Brit. J. industr. Med., 26, 294-301.

Selikoff, I. J., Hammond, E. C., and Churg, J. (1969) Mortality experiences of asbestos insulation workers 1943-68. Unpublished paper read at the International Conference on Penumoconiosis, Johannesburg.

Sleggs, C. A., Marchand, P., and Wagner, J. C. (1961). Diffuse pleural mesotheliomas in South Africa. S. Afr. med. J., 35, 28-34.

Wood, W. B., and Gloyne, S. R. (1934). Pulmonary asbestosis. A review of one hundred cases. Lancet, 2, 1383-1385.

Received for publication March 13, 1971 